\title{
Production and Characterization of Biodiesel Derived from a Novel Source Koelreuteria paniculata Seed Oil
}

\author{
Inam Ullah Khan, Zhenhua Yan*(i) and Jun Chen* \\ Key Laboratory of Advanced Energy Materials Chemistry (Ministry of Education), Renewable Energy \\ Conversion and Storage Center, College of Chemistry, Nankai University, Tianjin 300071, China; \\ 1120176003@mail.nankai.edu.cn \\ * Correspondence: yzh@nankai.edu.cn (Z.Y.); chenabc@nankai.edu.cn (J.C.)
}

Received: 2 January 2020; Accepted: 5 February 2020; Published: 11 February 2020

\begin{abstract}
Biodiesel is a clean and renewable fuel, which is considered as the best alternative to diesel fuel, but the feedstock contributes more than $70 \%$ of the cost. The most important constituent essential for biodiesel development is to explore cheap feedstock with high oil content. In this work, we found novel non-edible plant seeds of Koelreuteria paniculata (KP) with high oil contents of $28-30 \mathrm{wt} . \%$ and low free fatty acid contents $(0.91 \%)$, which can serve as a promising feedstock for biodiesel production. KP seed oil can convert into biodiesel/fatty acid methyl esters (FAMEs) by base-catalyzed transesterification with the highest biodiesel production of $95.2 \%$ after an optimization process. We obtained the optimal transesterification conditions, i.e., oil/methanol ratio (6:1), catalyst concentration $(0.32)$, reaction temperature $\left(65^{\circ} \mathrm{C}\right)$, stirring rate $(700 \mathrm{rpm})$, and reaction time $(80 \mathrm{~min})$. The physico-chemical properties and composition of the FAME were investigated and compared with mineral diesel. The synthesized esters were confirmed and characterized by the application of NMR $\left({ }^{1} \mathrm{H}\right.$ and $\left.{ }^{13} \mathrm{C}\right)$, FTIR, and GC-MS. The biofuel produced from KP seed oil satisfies the conditions verbalized by ASTM D6751 and EN14214 standards. Accordingly, KP source oil can be presented as a novel raw material for biofuel fabrication.
\end{abstract}

Keywords: Koelreuteria paniculata biodiesel; non-edible feedstock; transesterification; physicochemical characterization; optimization

\section{Introduction}

With the rising demand for energy, attention has been focused on alternate renewable fuel resources besides fossil fuels [1]. The research impetus of renewable fuel resources is on reduced net $\mathrm{CO}_{2}$ emission, thus controlling air, soil, and water pollution, and ultimately minimizing the well-being threat [2-4]. Biomass is the plant material derived from the reaction between $\mathrm{CO}_{2}$ in the air, water, and sunlight, via photosynthesis to produce carbohydrates that convert solar energy to chemical energy. About 170 billion tons of biomass produces every year on earth [5]. Biomass has always been a major source of energy for mankind; more than $90 \%$ of the living energy of about 2.5 billion people in the world is biomass energy. Biomass energy has the advantages of easy combustion, less pollution, and lower ash content, it has been the main source of human energy. The currently accounts for an estimated $10 \%-14 \%$ of the world's energy supply and more than $60 \%$ in underdeveloped regions, more than $90 \%$ of the living energy of about 2.5 billion people in the world is biomass energy [6-8]. However, the biomass energies are low calorific value and thermal efficiency, large volume, not easy to transport, and the thermal efficiency of direct combustion biomass is as low as $10 \%$ to $15 \%$. To increase the utilization of energy and make it more valuable, biomass energy can be converted into liquid and gaseous fuels as biodiesel through chemical routes [9-11]. The biodiesel fuels are oil esters [9] which have been an auspicious substitute source to fossil fuels because it is biodegradability, renewable 
nature, low emission lethal and good storing and transportation properties [2,12]. In recent years, the exploration and development of valuable energy plant seeds as high-efficiency biodiesel sources have become a research hotspot [13].

Currently, more than $95 \%$ of biodiesel is produced from edible oils, which seriously comprising deforestation and damage to wildlife [14] and reducing essential oil resources for the growing human population. Even though edible oils give enormous biodiesel production and easily transesterified because of their less free fatty acid contents $[12,15,16]$. However, they are reducing essential oil resources for the growing human population in many countries and regions; the use of edible oils for biodiesel production will direct competition with food uses [17]. The high cost of the raw material of biodiesel is the major barrier for its commercialization [18]. To control this situation, it is important to explore non-edible oil resources, which can be proved as cost-effective as well as resolving the food concerns [19]. In addition, the production of non-edible oils does not require ideal conditions [13]. Even non-fertile land, uncultivated land, road/field boundaries, disgraced forests, and irrigation canals can be used to produce non-edible oil crops [20]. Considering cost effectiveness, non-edible oil raw materials have been used in the production of biodiesel in various studies, including Croton megalocarpus [21], Prunus dulcis [22], Prunus sibirica [18], Rhazya stricta Decne [23], rubber seed oil [24], Silybum marianum L. [25], wild Brassica Juncea L. [26], etc. However, the challenge remains to produce high-quality biodiesel from cheap and available non-edible sources [27].

Koelreuteria paniculata (KP) belongs to the family Sapindaceae is a novel non-edible seed oil source that can be explored for biodiesel production. KP is rarely attacked by pests and grows in a wide range of soils, including high pH soils. The inflorescences are very remarkable and contain ellipsoid pods, which can produce huge amounts of seeds. A single average plant produces $15-20 \mathrm{~kg}$ seeds annually. Four to five hundred of KP trees can be planted per hectare area. Approximately one-hectare area will produce $115,000 \mathrm{~kg}$ seeds, the productivity of oil is about 30,000 kg per hectare area. KP species are originally from China, Japan, and Korea. It's been used as an ornamental plant and has no further uses. The KP tree is considered invasive in several areas due to the prolific seed production and bazillions of offspring. Due to all such characteristics, it is best suits to grown in waste and barren lands and use its seeds for alternative energy, which have $28 \%-30 \%$ oil contents (detailed descriptions are present in Supplementary Materials). However, to the best of our knowledge, the investigating KP seeds is a potential novel source of biodiesel.

In this work, we explored the efficacy of KP for the production and assessment of seed oil as biodiesels through a small budget and easy technique base-catalyzed transesterification method. The important parameters and their effects on the production and the fatty acid methyl ester (FAMEs) contents were optimized, comprising the oil to methanol molar ratio, $\mathrm{KOH}$ conc., temperature, time, and stirring intensity. The ester conversion and fatty acid composition were confirmed by Fourier transform infrared spectroscopy (FTIR), nuclear magnetic resonance (NMR) and gas chromatography-mass spectrometry (GC-MS). Its physical and chemical properties (density, kinematic viscosity, cloud point, cloud point, flash point, ignition point, etc.) were studied and compared with ASTM D6751 and EN14214. ICP-OES (inductively coupled plasma atomic emission spectrometry) and elements analyzer (EA) were used for elemental analysis, and the results showed that biodiesel was environmentally friendly.

\section{Materials and Methods}

\subsection{Materials}

Koelreuteria paniculata seeds used in the current research work were collected from the wild field in Binhai new area near Nankai University's new campus Tianjin, China, during months in November 2018. To remove the foreign matter, such as dirt, dust, chaff, and stones, as well as broken and immature seeds; the seeds were clean manually. As per instruction to control its original form and quality before any conditioning sealed in plastic bags at an ambient temperature of $25 \pm 3{ }^{\circ} \mathrm{C}$. 


\subsection{Chemicals}

Methanol 99-100\%, ethanol 99.8\%, ethanol 99\%-100\%, hydrochloric acid 37\%, $n$-hexane 96\% (Sinopharm Chemical Reagent Co., Ltd., Shanghai, China), cyclohexane (Macklin), $\geq 99.9 \%$, chloroform-d (Fluorochem, Hadfield, UK), acetonitrile, petroleum ether, phenolphthalein pH 8.2-9.8 (Sigma Aldrich, St. Louis, MO, USA), sodium hydroxide pellets $\geq 98 \%$, potassium hydroxide pellets $99.99 \%$, starch, acetone $(99 \%)$, sodium thiosulphate $(99.0 \%)$, sulphuric acid $98 \%$, (Aladdin, Shanghai, China), isopropanol, and bromine were obtained from Merck, Darmstadt, Germany.

\subsection{Preparation of Feedstock's/Soxhlet Extraction}

Solvent extraction is the process in which the oil is removed from seed through a liquid solvent, known as leaching. The KP were dried at $45{ }^{\circ} \mathrm{C}$ for $22 \mathrm{~h}$ after washing with deionized water to remove the dust (to completely finish the moisture), then ground with electrical grinder machine (XIANTAOPAI XTP-10000A, China). The oil was extracted by petroleum ether in a Soxhlet apparatus

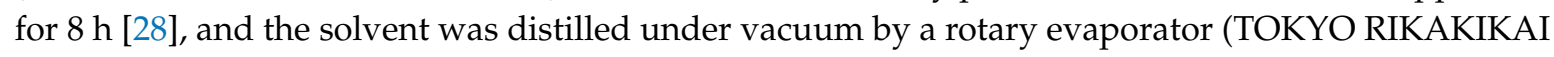
Co. Ltd., Tokyo, Japan, N-1210B). To remove the remaining moisture the obtained oil was dried with anhydrous sodium sulfate; then, for supplementary calculation and consumption, the obtained oil was filtered and put in a wrapped container at $5^{\circ} \mathrm{C}$.

\subsection{Experimental Procedure of Transesterification}

The transesterification (Figure 1) was done in a round bottom $2 \mathrm{~L}$ flask furnished with a magnetic stirrer, reflux condenser, sampling outlet, and thermometer. Before started the reaction, $500 \mathrm{~mL}$ seed oil was hated at $70{ }^{\circ} \mathrm{C}$. The reaction was done with a catalyst conc. $(\mathrm{KOH}) 0.32 \% \mathrm{w} / \mathrm{w}$ of the oil and oil to methanol molar ratio was 6:1. The freshly prepared $83.33 \mathrm{~mL}$ potassium methoxide solution was added in oil at $70{ }^{\circ} \mathrm{C}$ temperature and a constant stirring speed of $700 \mathrm{rpm}$ [29]. To confirm the comprehensive transformation of TAG to FAMEs, the stirring was continued for $80 \mathrm{~min}$. The mixture was relocated in a separatory tube funnel to separate the biodiesel and glycerin layers. The dense glycerin layer was detached. The upper biodiesel layer was then washed two to three times with hot distilled water to make it clean and clear. The product was dried through anhydrous sodium sulfate and evaporated the remaining methanol at $50{ }^{\circ} \mathrm{C}$.<smiles>[R]C(=O)OCC(OC([R])=O)C(C)OC([R])=O</smiles>

Triglyceride

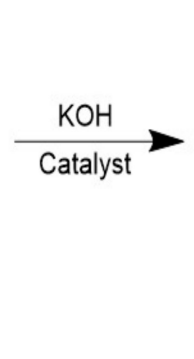

Methanol<smiles>OCC(O)CO</smiles>

Glycerol<smiles>[R]C(=O)OC</smiles><smiles>[R]C(=O)OC</smiles>

Biodiesel

Figure 1. Transesterification of Koelreuteria paniculata oil to biodiesel.

The product yield was premeditated by Equation (1),

$$
\text { Yield } \%=\frac{\text { Gram of biodiesel produced }}{\text { Gram of oil used }} \times 100
$$

\subsection{Analytical Study of KP Biodiesel}

The KP biodiesel (KPBD) produced through transesterification was examined for its eventual study using an EA (Vario EL CUBE, Hanau, Germany), which delivers C, H, and N outcomes, whereas the O value was examined from the difference. When the summation of $\mathrm{C}, \mathrm{H}$, and $\mathrm{N}$ values is deducted from 
100, it gives the O proportion, and for complete element, a study has been used ICP-OES (Spectro-blue, Kleve, Germany). The procedure is presented in Supplementary Materials Figure S3. The produced biodiesel was checked and verified with the Fourier transformed infrared spectrophotometer (Bruker vertex 70 FT-IR Spectrometer, Karlsruhe, Germany) with a resolution of $1 \mathrm{~cm}^{-1}$ and 15 scans, in the spectra range of $400-4000 \mathrm{~cm}^{-1}$. To describe various functional groups that originate in the found biodiesel, Nujol mull was used as a reference. NMR spectra were obtained with $\mathrm{CDCl}_{3}$ as a solvent on a (Bruker Avance Ш400 NMR Spectrometer, Karlsruhe, Germany) operating at $400 \mathrm{MHz}\left({ }^{1} \mathrm{H}-\mathrm{NMR}\right)$ or $100 \mathrm{MHz}\left({ }^{13} \mathrm{C}-\mathrm{NMR}\right)[30,31]$. Fatty acid composition of the prepared methyl esters was studied through GCMS (QP2010SE SHIMADZU, Kyoto, Japan). GC-MS conditions are listed in Table 1. The complete procedure is presented in Supplementary Materials Table S4.

Table 1. Gas chromatograph conditions.

\begin{tabular}{ll}
\hline \multicolumn{1}{c}{ Parameter } & Descriptions \\
\hline Column & QP2010SE, Shimadzu, PEG-20M \\
& Length: 30 m, Internal diameter: $0.32 \mathrm{~mm}$ \\
& Film thickness: $1 \mathrm{um}$ \\
Injector temperature & $220^{\circ} \mathrm{C}$ \\
Detector temperature (EI 250) & $210{ }^{\circ} \mathrm{C}$ \\
Carrier gas & Helium, flow rate $=1.2 \mathrm{~mL} \mathrm{~min}^{-1}$ \\
Injection & V = $1 \mathrm{uL}$ \\
Split ratio & Flow rate $=40: 1$ \\
Temperature program & Initial temperature $=100^{\circ} \mathrm{C}$ \\
& Rate of progression $=10^{\circ} \mathrm{C} \mathrm{min}$ \\
& Final temperature $=210^{\circ} \mathrm{C}, 20 \mathrm{~min}^{-1}$ \\
\hline
\end{tabular}

\subsection{Fuel Properties of KP Biodiesel}

Once the pure form of biodiesel was obtained, its physico-chemical characterization was evaluated through American standard testing material (ASTM) and European norm (EN). Moreover, the oil characterization of KP biofuel was matched to those of petro-diesel. The physiochemical characterization contains kinematic viscosity at $40^{\circ} \mathrm{C}$ (ASTM D445), density at $40{ }^{\circ} \mathrm{C}$ (ASTM D4052), flash point (ASTM D93), cloud point (ASTM D6751), pour point (ASTM D6751), acid value (ASTM D664), iodine value, oxidation stability at $110^{\circ} \mathrm{C}$ (EN 14112), ash content (ASTM D874), saponification value, sulfur content (ASTM D5459), fire point and specific gravity were calculated and matched with standards. The higher heating value (HHV) of KP biodiesel was also resolute based on the eventual study [32].

\section{Results and Discussion}

To make biodiesel from inedible KP seed (Plant photographs are present in Figure 2a,b), we first extract the oil from the seed of KP, which has an oil content of $28-30 \%$ by Soxhlet extraction (calculated based on dry seeds), as presented in Supplementary Materials Table S1. Then transesterification occurs to covert the crude oil to biodiesel with methanol using $\mathrm{KOH}$ as a catalyst. When the reaction of transesterification was completed, the catalyst was removed by washing and centrifugation, and the final process mixture was put in a separatory glass funnel tube (Figure 2c). Two different layers appeared in a separatory glass funnel, the upper layers contain biodiesel, methanol, and glycerin, and the lower layer contains glycerides, methanol, glycerol, and catalyst. We carried out three to four times deionized hot water washing to remove the excess methanol and glycerol from biodiesel. Finally, dry cleaning was done with silica gel to remove the leftover water in the final biodiesel product (Figure 2d) [33]. 
$\mathbf{a}$

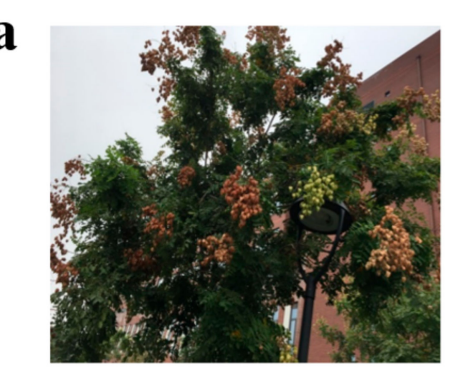

c

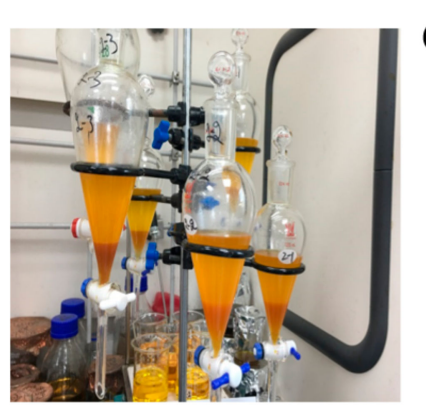

b

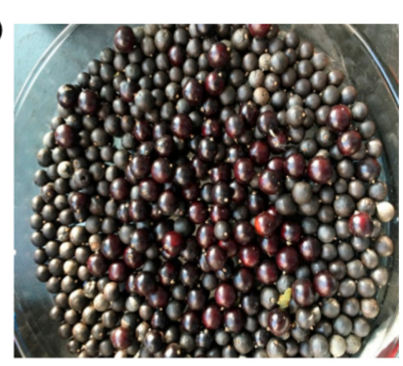

d

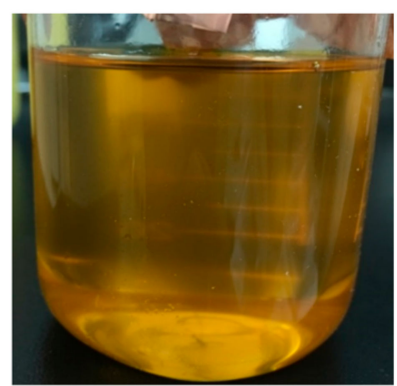

Figure 2. (a) Koelreuteria paniculata plant (KP) (b) KP seed (c) Transesterification (the process of optimization) (d) Pure KP biodiesel after processing.

\subsection{Koelreuteria Paniculata FAMEs Process of Optimizations}

To obtain the maximum biodiesel yield, we studied different parameters of the transesterification process, i.e., methanol to oil molar ratio, $\mathrm{KOH}$ concentrations, temperature, time, and stirring rate. Detailed processes of the optimization were listed in Supplementary Materials Table S2. The initial yield of FAMEs was only $89 \%$, which may have increased to $95.2 \%$ after the optimization. Five parameters were studied and analyzed under three or four different conditions to find out the optimal yield range of KP FAMES. The reason for using different parameters in different conditions is to check their best fit for the conditions to get the highest results. These five important variables and their analyses are explained respectively.

\subsubsection{Effect of Methanol to Oil Molar Ratio}

In both catalytic and non-catalytic reactions, the methanol/oil ratio is an important factor for the yield of methyl esters. Typically, transesterification (hydrolysis) needed 3 moles of alcohol for 1 mole of triglyceride to form 3 moles of fatty acid ester and 1 mole of glycerol. To obtained and evaluate the optimum molar ratio of methanol to oil, a range of ratios we have applied (4:1, 5:1, 6:1, and 7:1) in the experimentation (Figure 3a), while keeping other variables constant, such as temperature, stirring intensity and time. When the molar ratio was 6:1, the highest KPOB (KP oil biodiesel) yield was $94 \%$. A stoichiometric ratio of 4:1 provides the lowest oil conversion to biodiesel (79\%). It was further observed that if the methanol to oil ratio was lowered below the optimal range, no substantial conversion occurs in biodiesel production. The results showed that the overuse of methanol reduced FAMEs yield by 7:1 (86\%); because of the additional use of methanol, the separation of esters and glycerol's becomes more complicated. 

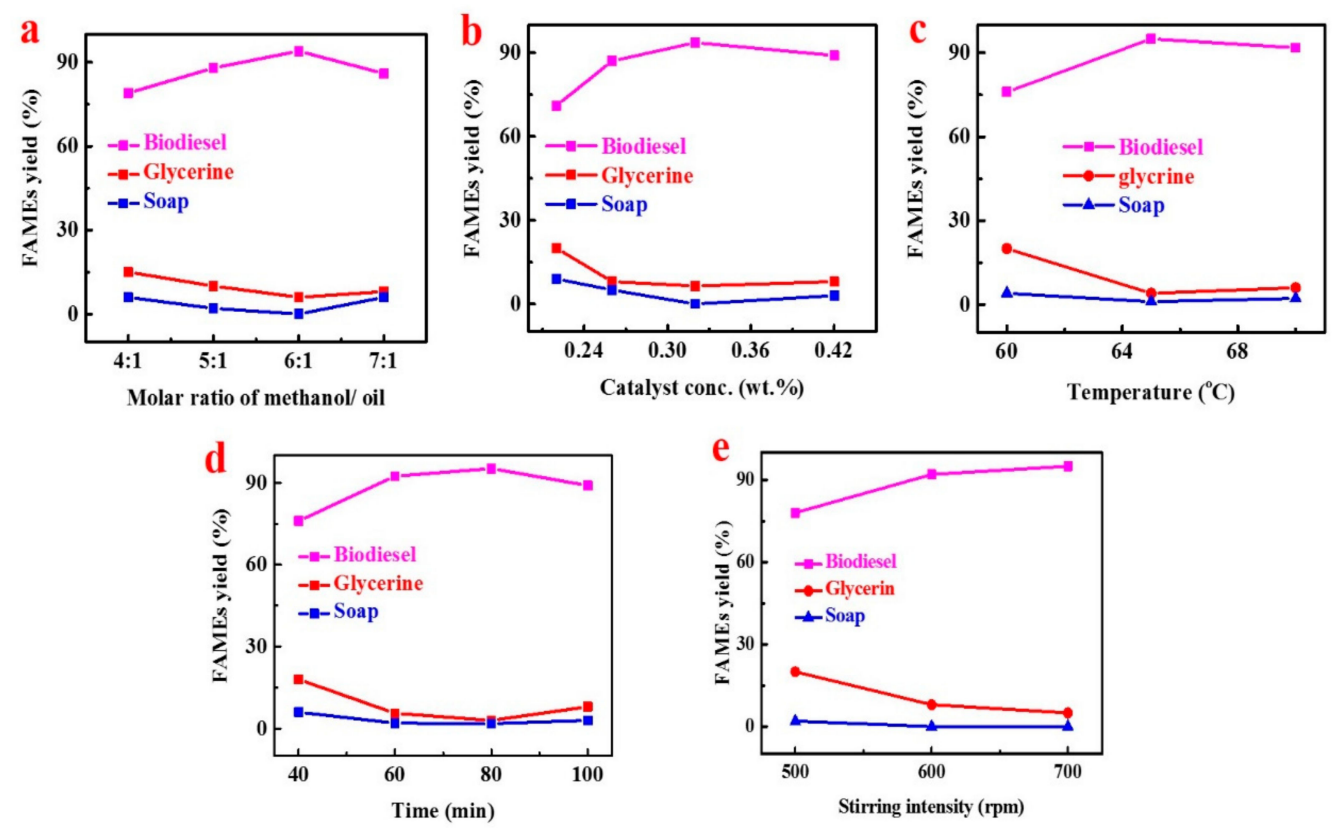

Figure 3. The effect of alcohol to oil molar ratio (a), $\mathrm{KOH}$ concentration (b), reaction temperature (c), time (d), and agitation rate (e) on KPOB production.

\subsubsection{Impact of Catalyst Concentration on FAMEs Production}

For the transesterification of triglycerides, various types of catalysts have been used, such as bases, acids, enzymes, or mixed catalysts. In the present study, $\mathrm{KOH}$ has been used as a base catalyst to convert the crude oil into fatty acid methyl ester. We achieved the highest biodiesel yield of $93.6 \%$. The influence of catalyst concentration ratio on the FAMEs production was assessed (Figure 3b), whereas the additional operative settings of the transesterification process were kept constant. It was noted that the highest KP oil biodiesel (KPOB) product yield was achieved at a catalyst concentration of $0.32 \mathrm{wt} . \%$. Additionally, it was witnessed that no important conversion occurred when the catalyst amount was higher than the optimal range.

\subsubsection{Influence of Temperature on Yield}

The reaction proportion was greatly affected by temperature. Usually, the reaction is carried out at a boiling point close to methanol $\left(60-70{ }^{\circ} \mathrm{C}\right)$ at atmospheric pressure. The transesterification reaction was carried out at three different temperatures $\left(60,65\right.$, and $\left.70^{\circ} \mathrm{C}\right)$ depending on the oil type. The methanol boiling point is $64.7^{\circ} \mathrm{C}$. Temperatures higher than the boiling point will burn alcohol, resulting in lower yields. Correspondingly, to evaluate the optimum temperature range regarding the highest FAMEs production, the different reaction temperature was used to get maximum KPOB biodiesel yield during the present experiment. It is clear from the result (Figure 3c) that at $65{ }^{\circ} \mathrm{C}$, maximum biodiesel production was achieved.

\subsubsection{Influence of Reaction Time on FAMEs Yield}

Transesterification reaction was carried out at an optimum reaction temperature $\left(65^{\circ} \mathrm{C}\right)$ for different periods from $40 \mathrm{~min}$ to $100 \mathrm{~min}$. It was detected that the reaction time was an important parameter which had a direct influence on the product yield. To get a higher yield and fully convert crude oil to biodiesel, the reaction time played a very important role [34]. As shown in (Figure 3d), the biodiesel conversion and reaction time were directly proportional to each other. At $80 \mathrm{~min}$, the highest biodiesel production (95.2\%) was obtained, while at $40 \mathrm{~min}$, the lowest biodiesel conversion was occurring $(76 \%)$. It has been further observed from work in the experiment that after $80 \mathrm{~min}$, the 
opposite reaction of hydrolysis started, and the FAMEs conversion ratio started decreasing, and longer reaction time resulted in a decrease in yield, which resulted in producing more soap and less FAMEs.

\subsubsection{Influence of Agitation Rate on Biodiesel Yield}

It was noticed through the transesterification process that the agitation rate could influence KPOB production, as shown in Figure 3e. The oil and fat were immiscible with the potassium hydroxide-methanol solution, so it was very important to mix by stirring during the transesterification reaction process. The reaction can become diffusion-controlled due to the slow rate of diffusion between the phases. Here we determined the direct relation between the KPOB production and the agitation strength, as with the increase in the stirring intensity, the biodiesel production increased. We evaluated that the $700 \mathrm{rpm}$ was the optimum stirring rate for the higher production of biodiesel (95\%) from KP seed oil to FAMEs. Though it was the same with the studies above [35] in which the authors concluded that a higher stirring intensity rate mixed the reaction well and gave the higher yield of methyl ester creations because elevated stirring strength promoted the homogenization of the reaction, which increased the yield of methyl ester.

\subsection{KP FAMEs Characterizations}

The physicochemical characterizations of the KP FAMEs were individually characterized (Table 2). The KP non-edible seed oil FAMEs had the following characteristics: viscosity $6.21 \mathrm{~mm}^{2} / \mathrm{s}$, density $0.879 \mathrm{~g} / \mathrm{cm}^{3}$, flashpoint $147^{\circ} \mathrm{C}$, ash content $0.002 \%$, cloud point $2{ }^{\circ} \mathrm{C}$ and pour point $-30{ }^{\circ} \mathrm{C}$, flaming point $175^{\circ} \mathrm{C}$, saponification value $176.4 \mathrm{mg} / \mathrm{g}$, specific gravity 0.88 , and cold filter plugging point $-18^{\circ} \mathrm{C}$.

Table 2. Physiochemical characterizations of KP seed oil biodiesel (KPSOB) in comparison with standards and plant fatty acid methyl esters (FAMEs).

\begin{tabular}{|c|c|c|c|c|c|c|c|}
\hline Parameters & EN 14214 & $\begin{array}{l}\text { ASTM } \\
\text { D-6751 }\end{array}$ & Pedro-diesel & $\begin{array}{l}\text { Present } \\
\text { Results/KРOB }\end{array}$ & DPSOME [36] & $\begin{array}{l}\text { SBOME } \\
{[37]}\end{array}$ & $\begin{array}{l}\text { DSOME } \\
{[38]}\end{array}$ \\
\hline Oil contents (wt.\%) & - & - & - & $28-30$ & $10.50 \pm 1.50$ & $15-20$ & 21.4 \\
\hline $\begin{array}{l}\text { Kinematic viscosity } \\
@ 40^{\circ} \mathrm{C}\left(\mathrm{mm}^{2} / \mathrm{s}\right)\end{array}$ & $3.5-5.0$ & $1.9-6.0$ & $1.3-4.1$ & 6.21 & $3.91 \pm 0.25$ & 4.50 & 4.33 \\
\hline $\begin{array}{l}\text { Acid value } \\
\left(\mathrm{mg} \mathrm{KOH} / \mathrm{g}^{-1}\right)\end{array}$ & Max. 0.50 & Max. 0.5 & - & 0.07 & $0.10 \pm 0.02$ & 0.15 & 0.10 \\
\hline $\begin{array}{l}\text { Saponification value } \\
\left(\mathrm{mg} \mathrm{KOH} / \mathrm{g}^{-1}\right)\end{array}$ & - & - & - & 176.4 & 224 & - & - \\
\hline $\begin{array}{l}\text { Iodine value } \\
\left(\mathrm{g} \mathrm{I}_{2} / 100 \mathrm{mg}\right)\end{array}$ & Max. 120 & Max. 120 & - & 80.7 & 48.51 & - & - \\
\hline Pour point $\left({ }^{\circ} \mathrm{C}\right)$ & - & - & -2.0 & -30 & -1 & -7 & - \\
\hline Cetane number & Min. 51 & $\begin{array}{l}\text { Min. } \\
47\end{array}$ & 49.7 & 51 & 59.75 & 58.1 & 51.9 \\
\hline Free fatty acid (\%) & - & - & - & 0.91 & - & - & - \\
\hline $\mathrm{HHV}$ & - & - & - & 23.39 & 39.52 & - & - \\
\hline Ash content & - & - & - & 0.002 & - & - & $<3$ \\
\hline $\begin{array}{l}\text { Specific gravity @15 } \\
\left({ }^{\circ} \mathrm{C}\right)\end{array}$ & - & - & - & 0.88 & - & - & - \\
\hline $\begin{array}{l}\text { Cold filter plug } \\
\text { point }\left({ }^{\circ} \mathrm{C}\right)\end{array}$ & Max. 19 & Max. 19 & -16 & -18 & - & - & -5 \\
\hline $\begin{array}{l}\text { Sulphated ash } \\
\text { content (wt.\%) }\end{array}$ & Max. 0.02 & - & - & 0.003 & - & 0.008 & 0.004 \\
\hline
\end{tabular}




\subsection{Physical and Fuel Characterizations}

The fuel and physicochemical properties of the produced KPOB were characterized by ASTM and EN standards. The results, as shown in Table 2, compared with the mentioned biofuel standards as ASTM D-6751 EN14214 and petrodiesel. The density of the KPBD at $40{ }^{\circ} \mathrm{C}$ was $0.879 \mathrm{~g} / \mathrm{cm}^{3}$, equivalent to the limits for petrodiesel $\left(0.834 \mathrm{~g} / \mathrm{cm}^{3}\right)$ and ASTM D-6751. The KPBD specific gravity value $(0.88)$ determined in this analysis was comparable to the ASTM value of petro-diesel. The most imperative stuff of biodiesel was viscosity since it distressed the action of fuel inoculation apparatus, mostly at the temperatures less than $15^{\circ} \mathrm{C}$ (viscosity affects fuel flow). The determined KPBD viscosity was $6.21 \mathrm{cps}$, somewhat higher than the ASTM D6751 rate of biodiesel and the ASTM rate of petroleum fuel, which needs further modification and improvement.

The pour point and cloud point dignified values for KPSO biodiesel KP seed oil (KPSO) biodiesel were -30 and $2{ }^{\circ} \mathrm{C}$, respectively, which met the diesel fuel limits specified in ASTM (Table 2). Flashpoints are parameters deliberated in the management, packing, and protection of fuels and combustible ingredients. The detected KPSO biodiesel flash point $\left(147^{\circ} \mathrm{C}\right)$ was higher than petroleum diesel and was within the ASTM range. This shows that KPBD is more safe and secure than fossil fuels. Though, a higher flash point may result in a lower capability of the compression ignition engine to burn than petroleum diesel. The quantity of FFA in the biodiesel fuel indicates acid value. The quantity higher than $0.50 \mathrm{mg} \mathrm{KOH} \mathrm{g}^{-1}$ may cause engine deterioration, $0.07 \mathrm{mg} \mathrm{KOH} \mathrm{g}^{-1}$ is the identified KPBD acid value, which was expressively less than the ASTM standard diesel fuel (Table 2).

\subsection{NMR Spectroscopy Analysis of Biodiesel}

\subsection{1. ${ }^{1} \mathrm{H}$ NMR Spectrum Analysis}

The KP FAMEs were characterized by ${ }^{1} \mathrm{H}$ NMR; the KP ${ }^{1} \mathrm{H}$ NMR spectrum is presented in Figure 4a and Supplementary Materials Table S4. In the ${ }^{1} \mathrm{H}$ NMR spectrum, the terminal methyl proton $\left(\mathrm{C}-\mathrm{CH}_{3}\right)$ appearance signals were detected between 0.88 and $0.90 \mathrm{ppm}$, and the aliphatic chain $\left(-\left(\mathrm{CH}_{2}\right) \mathrm{n}-\right)$ associated signals were observed between 1.25 and $1.31 \mathrm{ppm}$. The $\beta$-methylene ester $\left(\mathrm{CH}_{2}-\mathrm{C}-\mathrm{CO}_{2} \mathrm{Me}\right)$ bands appearance signals were detected around 1.58-1.65 ppm correspondingly, the methylene proton peaks near the base $\left(-\mathrm{CH}_{2}-\mathrm{C}=\mathrm{C}-\right)$ appear between 2.00 and $2.07 \mathrm{ppm}$ attached to the allylic group. The methylene proton peaks signal were attributed between 2.27 and $2.31 \mathrm{ppm}$ existing near the carbonyl group proton $\left(-\mathrm{CH}_{2}-\mathrm{COOMe}\right)$, the existence of a methylene proton $\left(-\mathrm{C}=\mathrm{C}-\mathrm{CH}_{2}-\mathrm{C}=\mathrm{C}-\right)$ between the allylic groups associated between $2.75-2.80 \mathrm{ppm}$, and the single sharp peak at $3.59 \mathrm{ppm}$ is expressed the ester bond $\left(\mathrm{CH}_{3} \mathrm{COO}-\mathrm{CH}\right)$ linked $\mathrm{CH}_{3}$ group. The proton $(-\mathrm{CH}=\mathrm{CH}-)$ from the glycerol moiety appears between 5.32-5.44 ppm.

\subsection{2. ${ }^{13} \mathrm{C}$ NMR Spectrum Analysis}

The KP biodiesel ${ }^{13} \mathrm{C}$ NMR spectrum is shown in Figure $4 \mathrm{~b}$ and Supplementary Materials Table S5. A signal which shows the occurrence of an ester carbonyl carbon (-COO-) was observed at $174.20 \mathrm{ppm}$. The band's signals were observed in the spectrum between 127.84 and $130.19 \mathrm{ppm}$ indicating the existence of unsaturation in the methyl ester. The occurrence of ester (C-O) methoxy carbon was observed at $51.38 \mathrm{ppm}$, due to the long carbon chain methylene carbon of the fatty acid methyl ester. The band's occurrence detected between 29.02 and $29.07 \mathrm{ppm}$, and the terminal carbon of the methyl group peaks was observed at $14.1 \mathrm{ppm}$, respectively. 
a

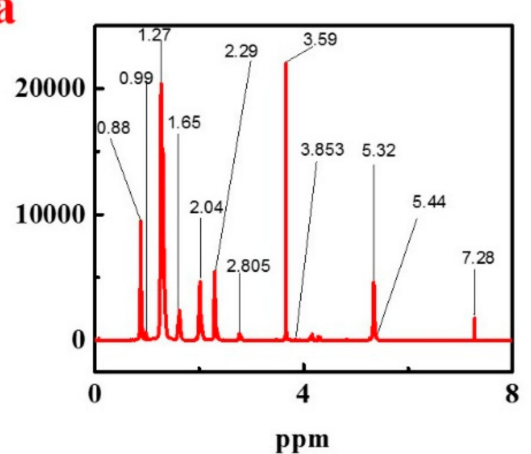

c

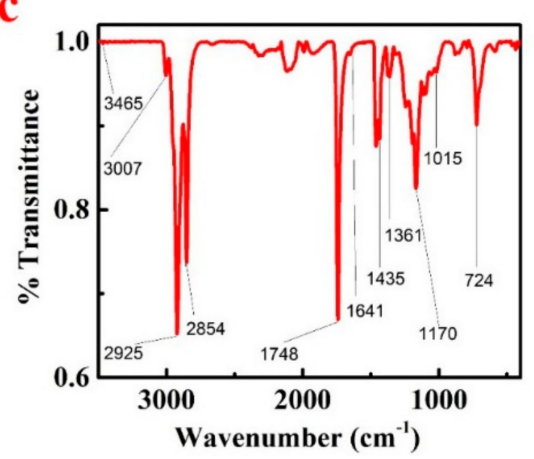

b

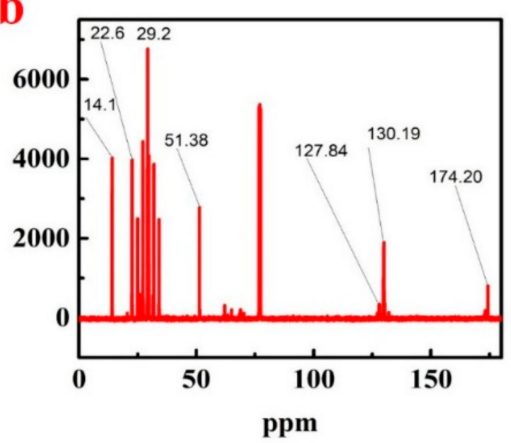

d

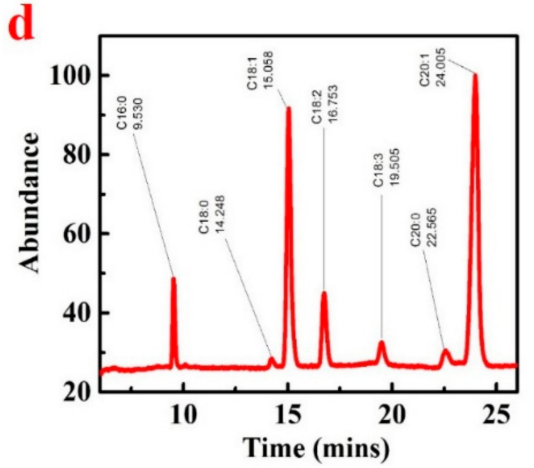

Figure 4. ${ }^{1} \mathrm{H}$ NMR (a), and ${ }^{13} \mathrm{C}$ NMR (b), KP (methyl ester) FTIR study (c), KP seed oil biodiesel GC-MS fatty acid compositions analysis (d).

\subsection{KP FAMEs FT-IR Spectroscopy Analysis}

To identify the functional groups and the bands corresponding to various stretching and bending vibrations in KP biodiesel samples, the FT-IR spectroscopy of the mid-infrared region has been used, as presented in Figure $4 \mathrm{c}$ and the Supplementary Materials Table S3. The two resilient ester representative absorption bands were detected from carbonyl $(\nu \mathrm{C}=\mathrm{O})$ around $1750-1730 \mathrm{~cm}^{-1}$ and $\mathrm{C}-\mathrm{O}$ at $1300-1000 \mathrm{~cm}^{-1}$ [39]. The stretching vibrations and bending vibrations $\left(\rho \mathrm{CH}_{2}\right)$ of $\mathrm{CH}_{3}, \mathrm{CH}_{2}$, and $\mathrm{CH}$ appeared at 2980-2950, 2950-2850, 3050-3000 $\mathrm{cm}^{-1}$, and at 1475-1350, 1350-1150, $722 \mathrm{~cm}^{-1}$, correspondingly [40]. The absorption peaks of the sample were detected in KP biodiesel to be 3465, $3007,2925,2854,1748,1641,1435,1361,1175,1015$, and $724 \mathrm{~cm}^{-1}$, respectively. The peaks presence in KP FAMEs at 1435 and $1170 \mathrm{~cm}^{-1}$ specifies the conversion of crude oil to biodiesel. Figure $4 \mathrm{c}$ shows the KPME FTIR spectrum, and the strong absorption peak at $2854 \mathrm{~cm}^{-1}$ and $2925 \mathrm{~cm}^{-1}$ is just because of the alkane group of $\mathrm{C}-\mathrm{H}$ stretching vibration. The $\mathrm{C}-\mathrm{H}$ bending vibration appears at $1435 \mathrm{~cm}^{-1}$ due to strong absorption. All of the single bands symbolize saturated functional groups. The $\mathrm{C}=\mathrm{O}$ stretching frequency peak at $1748 \mathrm{~cm}^{-1}$ is due to strong absorption, which is composed of an unsaturated functional group and is called an ester. Further, due to the $\mathrm{C}-\mathrm{O}$ stretching vibration of the ester, the strong band appeared at $1015 \mathrm{~cm}^{-1}$ and $1170 \mathrm{~cm}^{-1}$.

\subsection{GC/MS Analysis}

The biodiesel of KP crude oil modified by methyl ester was evaluated by gas chromatography and mass spectrometry. The GCMS spectral data are shown in Figure 4d. The NIST-14 library matching software was used to identify the peaks. After evaluation, each single peak was matched with fatty acid methyl ester [18]. The retention time and position of the determined peaks are presented in Table 3. 
Table 3. Koelreuteria paniculata seed oil biodisel fatty acid composition.

\begin{tabular}{|c|c|c|c|c|c|c|c|}
\hline S/ No & Fatty Acids & Retention Time & Number of Carbons & Fatty Acids (\%) & Chemical Name & Chemical Structure & Molecular Weight \\
\hline 1 & Palmitic acid & 9.530 & $\mathrm{C} 16: 0$ & 9.7 & Hexadecanoic acid, methyl ester & & 270 \\
\hline 2 & Stearic acid & 14.248 & $\mathrm{C} 18: 0$ & 1.8 & Methyl stearate & & 298 \\
\hline 3 & Oleic acid & 15.058 & C18:1 & 25.5 & 9-Octadecenoic acid (Z)-, methyl Ester & & 296 \\
\hline 4 & Linoleic acid & 16.753 & C18:2 & 8.5 & $\begin{array}{l}\text { 9, 12-Octadecadienoic acid }(Z, Z)-\text {, } \\
\text { methyl ester }\end{array}$ & & 294 \\
\hline 5 & $\alpha$-Linolenic acid & 19.505 & $\mathrm{C} 18: 3$ & 3.6 & $\alpha$-Linolenic acid & & 292 \\
\hline 6 & Arachidic acid & 22.565 & $\mathrm{C} 20: 0$ & 2.4 & Eicosanoic acid, methyl ester & & 326 \\
\hline 7 & Gondoic acid & 23.005 & C20:1 & 48.5 & Cis-11-Eicosenoic acid, methyl ester & & 324 \\
\hline
\end{tabular}




\subsection{ICP-OES and Elemental Analyzer (EA) Study}

The elements present in fuels are harmful because they cause many difficulties, such as promoting fuel degradation, corrosion of machinery, operational problems, environmental pollution and other social problems, as well as harmful effects on health [41]. The fundamentals whose quantity in biodiesel requires to be controlled are sodium $(\mathrm{Na})$ and potassium $(\mathrm{K})$ are important limiting quantities in the production mechanism of biodiesel, while phosphorus $(\mathrm{P})$ comes from raw materials and its controlling quantities are very important. The element concentration of Koelreuteria pniculata oil biodiesel (KPOBD) and HSD (high speed diesel) was compared. KP results confirm that the concentration of many base metals in KPOBD is lower than that in HSD. Elements such as $\mathrm{Ca}, \mathrm{Mg}, \mathrm{Na}$ and $\mathrm{K}$ in biodiesel directly enter the injector, and locomotive sediments stimulate the drainage and piston and pass through the filter plug [42]. K, Na, Mg, and Ca are present in Supplementary Materials Table S6. The KPOBD (6.14, $544.9,32.10,14.90 \mu \mathrm{g} / \mathrm{g})$ was lower as compared to $\operatorname{HSD}(213.3,868.3,35.6$ and $21.4 \mu \mathrm{g} / \mathrm{g})$. The highest acceptable concentration of $\mathrm{Na}$ and $\mathrm{K}$ in biodiesel was $5 \mathrm{mg} \mathrm{kg}^{-1}$, while $\mathrm{P}$ was $10 \mathrm{mg} \mathrm{kg}^{-1}$ (Figure 5).

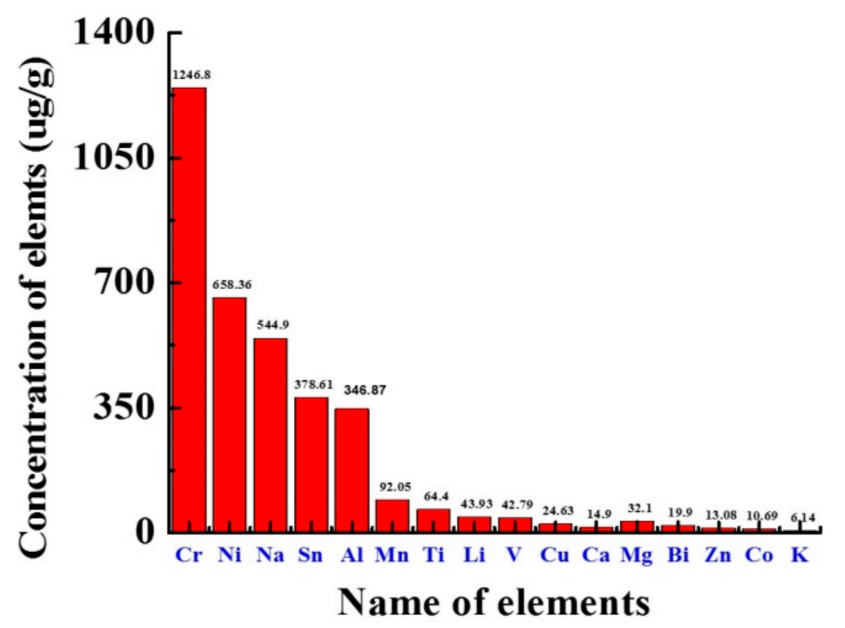

Figure 5. KPBD ICP-OES elemental analysis.

A detailed discussion of N, H, C, and O is shown in Table 4 and Supplementary Materials Figure S1. The petrodiesel has no oxygen, while biodiesel has oxygen, which is the main difference between biodiesel and petrodiesel. The main advantage of the presence of oxygen is that it can reduce ignition delay, increase combustion, and come entirely from fuel combustion, a purposeful cause that will reduce exhaust emissions, $\mathrm{CO}$, and particulate matter. Therefore, several scientists $[43,44]$ have proposed that biodiesel with higher oxygen content can significantly reduce particulate emissions from fuel engines. Table 4 specifies KP B100 as 12\%, whereas KP B100 for most biodiesel is approximately $10 \%[45,46]$. The higher hydrogen content $(12.73 \%)$ of biodiesel utilization makes KP biodiesel more attractive [47]. In gaseous and liquid fuels, hydrogen burns faster and hydrogen carbon is higher, which means the fuel has a higher molecular content of hydrogen, better combustion capacity and cleaner. Since hydrogen has a higher calorific value than carbon, the calorific value must increase as the ratio of hydrogen to carbon atoms increases. 
Table 4. Elemental analyzer study of KPBD and their comparison with other plant biodiesel.

\begin{tabular}{lllllll}
\hline Ultimate Analysis & KP-BD & $\begin{array}{l}\text { Pistachio } \\
\text { Shell [48] }\end{array}$ & $\begin{array}{l}\text { Peach } \\
\text { Stones [49] }\end{array}$ & $\begin{array}{l}\text { Apricot } \\
\text { Kernel } \\
\text { Shells [50] }\end{array}$ & $\begin{array}{l}\text { Cherry } \\
\text { Stones [51] }\end{array}$ & $\begin{array}{l}\text { Mahua } \\
\text { Seed [52] }\end{array}$ \\
\hline C\% & 72.54 & 42.41 & 45.92 & 47.33 & 52.48 & 61.24 \\
H\% & 12.73 & 5.64 & 6.09 & 6.37 & 7.58 & 8.40 \\
N\% & 2.73 & 0.070 & 0.580 & 0.370 & 4.54 & 4.12 \\
O\% & 12 & 51.87 & 47.38 & 45.93 & 35.30 & 25.50 \\
HHV (MJ/kg) & 23.39 & 22.21 & 24.07 & 24.29 & 24.11 & 25.30 \\
\hline
\end{tabular}

\section{Conclusions}

A novel plant seed of Koelreuteria paniculata was explored to produce biodiesel effectively with a simple, cheap, and energy-saving base-catalyzed methanol transesterification process. Through the optimization transesterification conditions: oil to methanol ratio (6:1), catalyst concentration $(0.32 \mathrm{~g}$ wt. $\%)$, temperature $\left(65^{\circ} \mathrm{C}\right)$, stirring rate $(700 \mathrm{rpm})$ and time $(80 \mathrm{~min})$, the highest biodiesel yield of $95.2 \%$ was obtained, which is favorable for commercial application. The physico-chemical characterizations of the biodiesel, i.e., flash point, pour point, cloud point, and density, are within the ASTM (D6751) and (EN14214) standards, the values of fuel properties were found to be comparable with mineral diesel, which is good for engine application. FTIR, NMR, and GC-MS analysis confirmed the complete conversion of crude oil to FAMEs. Finally, we used elements analysis ensured the environmentally friendly of biodiesel. Based on these analyses, it is stated that the biodiesel derived from KP seeds is considered to be an alternative and renewable source of fuel for energy production, which could be a promising substitute for petroleum diesel.

Supplementary Materials: The following are available online at http://www.mdpi.com/1996-1073/13/4/791/s1, Figure S1: KP plant Description, Figure S2: Mechanical extraction of seed, Figure S3: ICP-OES and EA study of KP biodiesel for elemental analysis. Figure S4: GC-MS Procedure, Table S1: Source collection, Oil extraction and transesterification of non-edible KP seed oil as biofuel, Table S2: KP FAMEs process of optimization, Table S3: FTIR data presenting various functional groups in KP FAMEs, Table S4: ${ }^{1} \mathrm{H}$ NMR spectroscopic data showing the chemical composition of various methyl esters (Methoxy proton) in KP biodiesel (FAMEs), Table S5: ${ }^{13} \mathrm{C}$ NMR spectroscopic data showing the chemical shift values corresponding to various structural features in KP (Methoxy carbon) FAMEs, Table S6: Shows KPBD ICP-OES elements concentration (ug/g) in comparison with petro-diesel.

Author Contributions: J.C. and Z.Y. supervised the research and revised the manuscript, Chen Hang help in seed collection and revised the manuscript, I.U.K., done the experiment and write the manuscript. All authors have read and agreed to the published version of the manuscript.

Funding: This work was supported by the National Natural Science Foundation of China (NSFC, 21801048), the National Programs for Nano-Key Project (2017YFA0206700), the National Natural Science Foundation of China (21835004), 111 Project from the Ministry of Education of China (B12015) and the Fundamental Research Funds for the Central Universities, Nankai University (63191711 and 63191416).

Conflicts of Interest: The authors declare no conflict of interest.

\section{References}

1. Röllin, H. Evidence for health effects of early life exposure to indoor air pollutants: What we know and what can be done. J. Clean Air 2017, 27, 2-3. [CrossRef]

2. Sharma, Y.C.; Singh, B.; Upadhyay, S.N. Advancements in development and characterization of biodiesel. A review. Fuel 2008, 87, 2355-2377. [CrossRef]

3. Xue, B.J.; Luo, J.; Zhang, F.; Fang, Z. Biodiesel production from soybean andJatropha oils by magnetic $\mathrm{CaFe}_{2} \mathrm{O}_{4}-\mathrm{Ca}_{2} \mathrm{Fe}_{2} \mathrm{O}_{5}$-based catalyst. Energy 2014, 68, 584-591. [CrossRef]

4. Samadi, S.; Karimi, K.; Behnam, S. Simultaneous biosorption and bioethanol production from lead-contaminated media by mucor indicus. J. Biofuel Res. 2017, 4, 545-550. [CrossRef]

5. McKendry, P. Energy production from biomass conversion technologies. Bioresour. Technol. Part A 2002, 83, 47-54. [CrossRef] 
6. Warren Spring Laboratory. Fundamental Research on the Thermal Treatment of Wastes and Biomass: Literature Review of Part Research on Thermal Treatment of Biomass and Waste; B/T1/00208/Rep/1; ETSU: Johnson City, TN, USA, 1993.

7. Khan, I.U.; Yan, Z.H.; Chen, J. Optimization, transesterification and analytical study of Rhus typhina non-edible seed oil as biodiesel production. Energies 2019, 12, 4290.

8. Guedes, R.E.; Luna, A.S.; Torres, A.R. Operating parameters for bio-oil production in biomass pyrolysis: A review. J. Anal. Appl. Pyrol. 2018, 129, 134-149. [CrossRef]

9. Mucak, A.; Karabektas, M.; Hasimoglu, C.; Ergen, G. Performance and emission characteristics of a diesel engine fuelled with emulsified biodiesel-diesel fuel blends. Int. J. Autom. Eng. Technol. 2016, 5, 176-185. [CrossRef]

10. Chew, K.W.; Yap, J.Y.; Show, P.L.; Suan, N.H.; Juan, J.C.; Ling, T.C.; Lee, D.J.; Chang, J.S. Microalgae biorefinery: High value products perspectives. Bioresour. Technol. 2017, 229, 53-62. [CrossRef]

11. Martín-Lara, M.A.; Ortuño, N.; Conesa, J.A. Volatile and semivolatile emissions from the pyrolysis of almond shell loaded with heavy metals. Sci. Total Environ. 2018, 613-614, 418-427.

12. Tremblay, A.Y.; Montpetit, A. The in-process removal of sterol glycosides by ultrafiltration in biodiesel production. J. Biofuel Res. 2017, 4, 559-564. [CrossRef]

13. Rashed, M.M.; Kalam, M.A.; Masjuki, h.H.; Mofijur, M.; Rasul, M.G. Performance and emission characteristics of a diesel engine fueled with palmjatropha, and moringa oil methyl ester. Ind. Crops Prod. 2016, 79, 70-76. [CrossRef]

14. Gui, M.M.; Lee, K.T.; Bhatia, S. Feasibility of edible oil vs. non-edible oil vs. waste edible oil as biodiesel feedstock. Energy 2008, 33, 1646-1653. [CrossRef]

15. Atadashi, I.M.; Aroua, M.K.; Abdul Aziz, A.R.; Sulaiman, N.M.N. Production of biodiesel using high free fatty acid feedstocks. Renew. Sustain. Energy Rev. 2012, 16, 3275-3285. [CrossRef]

16. Shafiei, A.; Rastegari, H.; Ghaziaskar, H.S.; Yalpani, M. Glycerol transesterification with ethyl acetate to synthesize acetins using ethyl acetate as reactant and entrainer. J. Biofuel Res. 2017, 4, 565-570. [CrossRef]

17. Gandhi, M.; Ramu, N.; Bakkiya Raj, S. Methyl ester production from Schlichera oleosa. Int. J. Pharm. Sci. Res. 2011, 2, 1244-1250.

18. Wang, L.B.; Yu, H.Y. Biodiesel from Siberian apricot (Prunus sibirica L.) seed kernel oil. Bioresour. Technol. 2012, 112, 335-338. [CrossRef] [PubMed]

19. Silitonga, A.S.; Masjuki, H.H.; Mahlia, T.M.I.; Ong, H.C.; Atabani, A.E.; Chong, W.T. A global comparative review of biodiesel production from jatropha curcas using different homogeneous acid and alkaline catalysts: Study of physical and chemical properties. Renew. Sustain. Energy Rev. 2013, 24, 514-533. [CrossRef]

20. Ashraful, A.M.; Masjuki, H.H.; Kalam, M.A.; Rizwanul Fattah, I.M.; Imtenan, S.; Shahir, S.A.; Mobarak, H.M. Production and comparison of fuel properties, engine performance, and emission characteristics of biodiesel from various non-edible vegetable oils: A review. Energy Convers. Manag. 2014, 80, 202-228. [CrossRef]

21. Aliyu, B.; Agnew, B.; Douglas, S. Croton megalocarpus (Musine) seeds as potential source of bio-diesel. Biomass Bioenergy 2010, 34, 1495-1499. [CrossRef]

22. Atapour, M.; Kariminia, H.R. Characterization and transesterification of Iranian bitter almond oil for biodiesel production. Appl. Energy 2011, 88, 2377-2381. [CrossRef]

23. Nehdi, I.A.; Sbihi, H.M.; Al-Resayes, S.I. Rhazya stricta Decne seed oil as an alternative, non-conventional feedstock for biodiesel production. Energy Convers. Manag. 2014, 81, 400-406. [CrossRef]

24. Reshad, A.S.; Tiwari, P.; Goud, V.V. Extraction of oil from rubber seeds for biodiesel application: Optimization of parameters. Fuel 2015, 150, 636-644. [CrossRef]

25. Fadhil, A.B.; Aziz, A.M.; Altamer, M.H. Biodiesel production from Silybum marianum L. seed oil with high FFA content using sulfonated carbon catalyst for esterification and base catalyst for transesterification. Energy Convers. Manag. 2016, 108, 255-265. [CrossRef]

26. Aldobouni, I.A.; Fadhil, A.B.; Saied, I.K. Optimized alkali catalyzed transesterification of wild mustard (Brassica juncea L.) seed oil. Energy Sources Part A 2016, 38, 2319-2325. [CrossRef]

27. Chen, Y.H.; Chen, J.H.; Luo, Y.M. Complementary biodiesel combination from tung and medium-chain fatty acid oils. Renew. Energy 2012, 44, 305-310. [CrossRef] 
28. Kpikpi, W.M. Jatropha curcus as a vegetable source of renewable energy. ANSTI Sub. Network Meeting on Renew. Energy 2002, 3, 18-22.

29. Ahmad, M.; Khan, M.A.; Zafar, M.; Sultana, S. Practical Handbook on Biodiesel Production and Properties; Taylor and Francis: Boca Raton, FL, USA, 2012; pp. 1-157.

30. Bhandari, D.C.; Chandel, K.P.S. Status of rocket germplasm in India: Research accomplishments and priorities. In Rocket: A Mediterranean Crop for the World; International Plant Genetics Research Institute: Legnaro, Italy, 1996; Volume 67, pp. 13-14.

31. Christie, W.W. Lipid Analysis, 3rd ed.; Oily Press: Bridgwater, UK, 2003.

32. Sen, N.; Kar, Y. Pyrolysis of black cumin seed cake in a fixed-bed reactor. Biomass Bioenerg. 2011, 3, 4297-4304. [CrossRef]

33. Usta, N.; Öztürk, E.; Can, O.; Conkur, E.S.; Nas, S.; Çon, A.H. Combustion of biodiesel fuel produced from hazelnut soapstock/waste sunflower oil mixture in a diesel engine. Energy Convers. Manag. 2005, 46, 741-755. [CrossRef]

34. Kafuku, G.; Mbarawa, M. Effects of biodiesel blending with fossil fuel on flow properties of biodiesel produced from non-edible oils. Int. J. Green Energy 2010, 7, 434-444. [CrossRef]

35. Vedaraman, N.; Puhan, S.; Nagarajan, G.; Velappan, K.C. Preparation of palm oil biodiesel 305 and effect of various additives on NOx emission reduction in B20: An experimental study. Int. J. Green Energy 2011, 8, 383-397. [CrossRef]

36. Abdelrahman, B.F.; Mohammed, A.A.; Liqaa, I.S. Date (Phoenix dactylifera L.) palm stones as a potential new feedstock for liquid bio-fuels production. Fuel 2017, 210, 165-176.

37. Karmakar, A.; Karmakar, S.; Mukherjee, S. Properties of various plants and animal feedstock's for biodiesel production. Bioresour. Technol. 2010, 101, 7201-7210. [CrossRef] [PubMed]

38. Wang, R.; Zhou, W.W.; Hanna, M.A.; Zhang, Y.P.; Bhadury, P.S.; Wang, Y.; Song, B.A.; Yang, S. Biodiesel preparation, optimization, and fuel properties from non-edible feedstock, Datura stramonium L. Fuel 2012, 91, 182-186. [CrossRef]

39. Soares, I.P.; Rezende, T.F.; Silva, R.C.; Castro, E.V.R.; Fortes, I.C.P. Multivariate calibration by variable selection for blends of raw soybean oil/biodiesel from different sources using Fourier Transform Infrared Spectroscopy (FT-IR) spectra data. Energy Fuels 2008, 22, 2079-2083. [CrossRef]

40. Safar, M.; Bertrand, D.; Robert, P.; Devaux, M.F.; Genut, C. Characterization of edible oils, butters and margarines by Fouier Transform Infrared Spectroscopy with attenuated total reflectance. J. Am. Oil Chem. Soc. 1994, 71, 371-377. [CrossRef]

41. Schober, S.; Mittelbach, M. Influence of Diesel Particulate Filter Additives on Biodiesel Quality. Eur. J. Lipid Sci. Technol. 2005, 107, 268-271. [CrossRef]

42. McCormick, R.L.; Alleman, T.L.; Ratcliff, M.; Moens, L.; Lawrence, R. Survey of the Quality and stability of Biodiesel and Biodiesel Blends in the United States in 2004. In Technical Report of National Renewable Energy Laboratory; National Renewable Energy Laboratory (NREL): Golden, CO, USA, 2005.

43. Song, H.; Quinton, K.S.; Peng, Z.; Zhao, H.; Ladommatos, N. Effects of Oxygen Content of Fuels on Combustion and Emissions of Diesel Engines. Energies 2016, 9, 28. [CrossRef]

44. Mwang, J.K.; Lee, W.J.; Chang, Y.C.; Chen, C.Y.; Wang, L.C. An overview: Energy saving and pollution reduction by using green fuel blends in diesel engines. Appl. Energy 2015, 159, 214-236. [CrossRef]

45. Singh, D.; Subramanian, K.A.; Juneja, M.; Singh, K.; Singh, S. Investigating the effect of fuel cetane number, oxygen content, fuel density, and engine operating variables on NOx emissions of a heavy duty diesel engine. Environ. Prog. Sustain. Energy 2017, 36, 214-221. [CrossRef]

46. Demirbas, A. Combustion Efficiency Impacts of Biofuels. Energy Sources Part A 2009, 31, 602-609. [CrossRef]

47. Huber, G.W.; Iborra, S.; Corma, A. Synthesis of transportation fuels from biomass: Chemistry, catalysts, and engineering. Chem. Rev. 2006, 106, 4044-4098. [CrossRef] [PubMed]

48. Acıkalın, K.; Karaca, F.; Bolat, E. Pyrolysis of pistachio shell: Effects of pyrolysis conditions and analysis of products. Fuel 2012, 95, 169-717. [CrossRef]

49. Uysal, T.; Duman, G.; Onal, Y.; Yasa, I.; Yanik, J. Production of activated carbon and fungicidal oil from peach stone by two-stage process. J. Anal. Appl. Pyrol. 2014, 108, 47-55. [CrossRef]

50. Demiral, I.; Kul, S.C. Pyrolysis of apricot kernel shell in a fixed-bed reactor: Characterization of bio-oil and char. J. Anal. Appl. Pyrol. 2014, 107, 17-24. [CrossRef] 
51. Duman, G.; Okutucu, C.; Ucar, S.; Stah, R.; Yanik, J. The slow and fast pyrolysis of cherry seed. Bioresour. Technol. 2011, 102, 1869-1878. [CrossRef]

52. Pradhan, D.; Singh, R.K.; Bendu, H.; Mund, R. Pyrolysis of Mahua seed (Madhuca indica)—Production of biofuel and its characterization. Energy Convers. Manag. 2016, 108, 529-538. [CrossRef]

(C) 2020 by the authors. Licensee MDPI, Basel, Switzerland. This article is an open access article distributed under the terms and conditions of the Creative Commons Attribution (CC BY) license (http://creativecommons.org/licenses/by/4.0/). 